\title{
Local Government Capacity on E-Participation in Tanzania
}

\author{
Stella Malangalila Kinemo \\ Senior Lecturer $(\mathrm{PhD})$, Mzumbe University, Tanzania \\ School of Public Administration and Management \\ E-mail: smkinemo@mzumbe.ac.tz
}

Received: Nov. 17, 2019 Accepted: Dec. 16, 2019 Online published: Dec. 24, 2019

doi:10.5296/jpag.v9i4.16126 URL: https://doi.org/10.5296/jpag.v9i4.16126

\begin{abstract}
Rapid development of information has made governments to employ e-participation by using ICT tools for the purpose of involving citizens in government policy issues. The purpose of this study was to examine e-participation tools and local government capacity on e-participation with reference to technical, financial and human resource in Tanzania. The study employed descriptive statistics whereby qualitative and quantitative approaches were applied. The data collection methods used were questionnaire and in depth interviews. Quantitative data were analysed using descriptive statistics while qualitative data was analysed using content analysis. The study findings revealed that the municipality does not have adequate technical and financial capacity for e-participation. The findings also revealed that websites and emails were the only e-participation tools used by the municipality. To improve capacity of Kinondoni Municipality in e-participation it is recommended that more funds should be injected to ICT infrastructures and that staff should be recruited and trained for ICT use.
\end{abstract}

Keywords: capacity, e- participation

\section{Introduction}

E-participation is a socio-technical field that targets at enabling citizens to participate in a dialogue with their governments using communication technologies such as e-forums, e-mails, and other different Information Technologies (ITs). This part of interest, named e-participation, centres on the structure and processes through which ICT underpins connections among governments, citizens and public organizations. Governments have an obligation to inspire its people to effectively play part in public decision making. The significance of the participation of the public has been extensively acknowledged. For certain 
reasons, the participation level of the citizen to the local governments has been going down for long time. The traditional participation level of the citizens to the local government results it to face difficult to shield from dissolving. With its quick development of IT and its wide use in private sectors for connecting with customers, governments began to use ICT instruments as appropriate methodologies for individuals to engage, and raise the e-support.

The performance of municipality in e-participation in African nations is especially significant. However, the vast majority of this data is not generally available to the larger part, particularly those in the provincial territory. Portions of the attributes that add to this circumstance incorporate absence of access to internet, expense of ICTs and high neediness and lack of education. As indicated by UN (2008) these variables have made African nations score beneath the world average in the worldwide e- participation position.

Tanzania as one country from this category has also taken initial steps of adapting and excising e-participation in local governments. The country has been experiencing some obstacles from different areas in applying e-participation in local governments. Such challenges include lack of citizen's awareness, poor ICT infrastructures, government workers preparedness and low marginal propensity to change of its stakeholders. The objective of the study was to examine the capacity of Kinondoni municipality on e-participation in relation to technical and financial factors.

\section{Literature Review}

\subsection{The Concept of E-Participation}

The e-participation concept is one branch of e-government and is concentrated specifically on the citizen's participation in the processes of government policy-formulation. Participation can include all levels of the policy cycle, from agenda setting and problem formulation to decision-making and evaluation. Normally the first point of contact for citizens is the municipality. This is a vital level of government for e-participation as citizens feel they are more personally involved and have a greater expectation about the effect of their participation in their municipality (Albrecht et al., 2008).

White (1997) defined e-participation as "the use of Information Technologies to participate in dialogue among citizens and between citizens and selected or appointed officials over public policy issues." This definition clarifies the meaning of e-participation by emphasizing citizen engagement in government issues. That is, e-participation serves not only as a communication network which e-participants express themselves, but also plays as an online community providing e-participants with an opportunity to build online networks. Citizen-initiated e-participation often involves a deliberative communication mode in which citizens enjoy many-to-many communications. This implies that e-participants not only communicate with public administrators, but that they also observe, make comments on the inputs of others as well as respond to the comments of others. Thus, this study will focus on the definition of e-participation basing on White perspective. E-decision making, e-consultation and e-information are the three types of e-participation. E-decision making is used by government to enable citizens to contribute their ideas during decision making process. E-information 
enables public information to be provided to the citizens. Thus this study focuses on the capacity of local government on e-information rather than e-decision making and e-consultation.

According to Albrecht et al. (2008), there are two fundamental reasons why e-Participation is being used by the government to supplement current offline participation approaches. The primary reason is, ICT can be used to help the current cooperative methods of policy approach, which exist to enhance the quality of the process, yet in addition to build the representation and the contribution from citizens. Kyere and Kumah (2017) argue that e-participation has been a significant channel in consulting, issuing public information, improving active citizen's participation, providing feedback to the citizens, monitoring and evaluating government projects and its implementation as well as making government responsive, accountable and transparent in its total political discourse. The implementation and progress of e-participation in the local governments rely on the government's technical, financial, political, administrative capacity as well as the willing of the local governments to encourage the electronic participation of the citizen (Zheng, 2015). These factors influence governments in different countries to perform differently in e-participation at local government level.

In spite of the efforts made by Tanzanian government to embark on the ICT usage, e-participation adoption has been quite slow. The slow adoption of e-participation restricts citizens to access relevant information in the country. Though the application of e-participation by the public has been extensively studied, there remains a difference in e-participation performance across different countries.

As it has been indicated in the literature by O'Donnell, Boyle, \& Timonen (2003) that, e-participation expands and develops political participation by empowering citizens to associate or link with each other, with civil servants, and with elected leaders by means of ICT. A more process settled meaning of e-participation is ICT-upheld participation in processes associated with government and administration. Processes include service delivery, policy making, decision making, and administration (Macintosh, 2008). This definition focuses only on electronic voting processes and decision-making.

Study by Macintosh and Whyte (2008) see e-participation as e-government service that is available in the websites of the government as a major aspect of e-government services provided by government agencies. They further elaborate e-participation as the application of web technologies to provide important information and to support 'top-down' participation, or to raise 'ground-up' efforts to enable citizens to experience support from their local governments.

\subsection{Local Government Capacity and E-participation}

Kim \& Bretschneider (2004) define technical capacity as ability of local government to utilize IT for the purpose of implementing its objectives. Apart from other factors which are needed for effective implementation of e-government adoption, technical capacity is also important (Reddick \& Norris, 2013). It is obvious that e-participation can be effective with the growth of ICT in local government. The capacities have been grouped into two 
non-human capacity and human capacity. The non-human capacity refers to IT infrastructure such as websites and internets while human capacity means the skills which staff needs to possess to be able to use IT infrastructure. The local governments' technical capacity is also associated with the workers who are mainly employed for management of the ICT equipments. Therefore, basing on the different definitions provided by different authors in the literature review, in this study technical capacity refers to capacity of local governments to utilise IT for e-participation. The extent to which workers obtain timely IT training and whether the municipal has satisfactory IT facilities were studied.

E-participation growth requires financial resources to procure IT infrastructure and IT expertise. Performance cannot be upgraded and high-quality services cannot be delivered without a basis of sufficient financial resources. Kim and Bretschneider (2004) emphasize that e-participation requires sufficient funds for procuring of facilities and updating of software as well as the providing training to the local government workers. The financial capacity is one of the important factors that governments should take into consideration in e-participation. Local governments need to have a sound capacity of financial resources to meet the expense (Kim \& Bretschneider, 2004). In this study the capacities which were considered relate to financial resources in the municipality for developing IT; availability of IT expertise; and training of IT staff.

\subsection{Tools for E-participation}

According to Shanab and Al-Dalou (2012) there are different technical tools for e-information, e-consultation and e- decision making. Phang and Kankanhalli (2008) indicated best ICT tools on e-participation. They claimed that in order to achieve for information exchange, the best ICT tools is online chat and online discussion forum. Likewise, tools like discussion forum, e-profiling, e-mail, online chat with login system, and video conferencing are viewed as the best tools for achieving the e-participation objectives. According to Saebo, Rose and Flak (2008) there are different e-participation technologies such as online forum, and GIS which can be useful in planning. Moreover, to get citizens' views about the policies under consideration, tools like web comment forms, online survey questionnaires, and data analysis tools are much applicable. It is further emphasized that ICT enables citizens to participate in the process of decision-making (Sobaci, 2010). Moreover the ICT tools enables implementation of decision making process in public policies. Networks are important in the process of citizen participation and are basis for implementing e-democracy (Glassey, 2010).

\subsection{Empirical Studies on E- participation}

A study by Kearns, Bend and Stern (2002) on e-participation in local government shows that, e-participation levels are low and are greatly focused on e-mail links among different people and council officers; Use of intelligent web-dialogue spaces and e-mail dialogue groups is occurring in not many cases. The efforts of e-participation are not efficiently advertised by many local authorities. Insufficient consideration is being paid to endeavours to make e-participation sincerely inclusive of hard to reach groups. The study concluded that in spite of the fact that e-participation equipment such as e-mail dialogue groups and web dialogue spaces can possibly assist local authorities in meeting the assortment of threats and 
opportunities presently being confronted.

Zheng (2015) performed a study on "Performance of the government on e-participation" The findings showed that there is an influence on e-participation when local governments have capacity. He emphasized that if local authorities have financial and technical capacity there will be effective e-participation. The willingness of government is also considered as factor to e-participation progress. However the focus of this study was not on the willingness of government rather on financial, human and technical capacity.

A study done by Krishnan et al. (2012) on contextual factors, e-participation, and e-government development done in Singapore revealed that there is relationship between human capital, ICT infrastructure, and e-participation with growth of e-government. The study also revealed that the development of e-government has relationship with e-information sharing, e-participation, and e-decision-making. Furthermore, all dimensions of e-participation mediate the influence of human capital and ICT infrastructure on the growth of e-government.

Kyere and Kumah (2017) did a study on "Imperative of e-participation in Sustainable Community Development" in Ghana. The study showed a significance of ICT for the adoption of e-participation in local governments in Ghana. They concluded that e-participation improves the effectiveness and efficiency of the local governments in delivering its services to the public to ensure sustainable development. The study recommended that governments should ensure an availability of important ICT infrastructure and training of personnel in the local governments in order to ensure active e-participation.

\subsection{Resource Based View Theory}

The Resource Based View Theory states that, firm's resources are a determining factor of improving performance in the organisation (Barney et al., 2001). The theory puts emphasis on the importance of resources in the organization in implementing organizational objectives. It states that organization's performance is driven by availability of resources that are needed by a particular industry (Singh \& Mahmood, 2014). The Resource Based Theory helps in defining the resources available within the organization and link with the capabilities of the organization (Colbert 2004). Hart (1995) argues that the technology capacity, human resources, raw materials, the loyalty of the customers and financial supports are the most important resources needed by the organizations. Other resources which facilitate implementation of organization strategies are internal assets, organizational processes, capabilities, knowledge, information (Okioga, 2012). The theory is relevant to the study because it shows the importance of resources to e-participation in local government.

\subsection{Conceptual Framework}

Figure 1 shows the conceptual framework of the study. The underlying assumption for the study is that availability of tools for e-participation which leads to effective implementation of e-participation was regarded as dependent variable to capacity of KMC. The technical capacity and financial capacity of the KMC were regarded as dependent variables of the study. Capacity of KMC on e-participation may affect citizen's participation in the processes of 
government policy issues. Financial capacity may also influence technical capacity of KMC in terms of ability to utilize IT for the purpose of implementing e-participation activities.

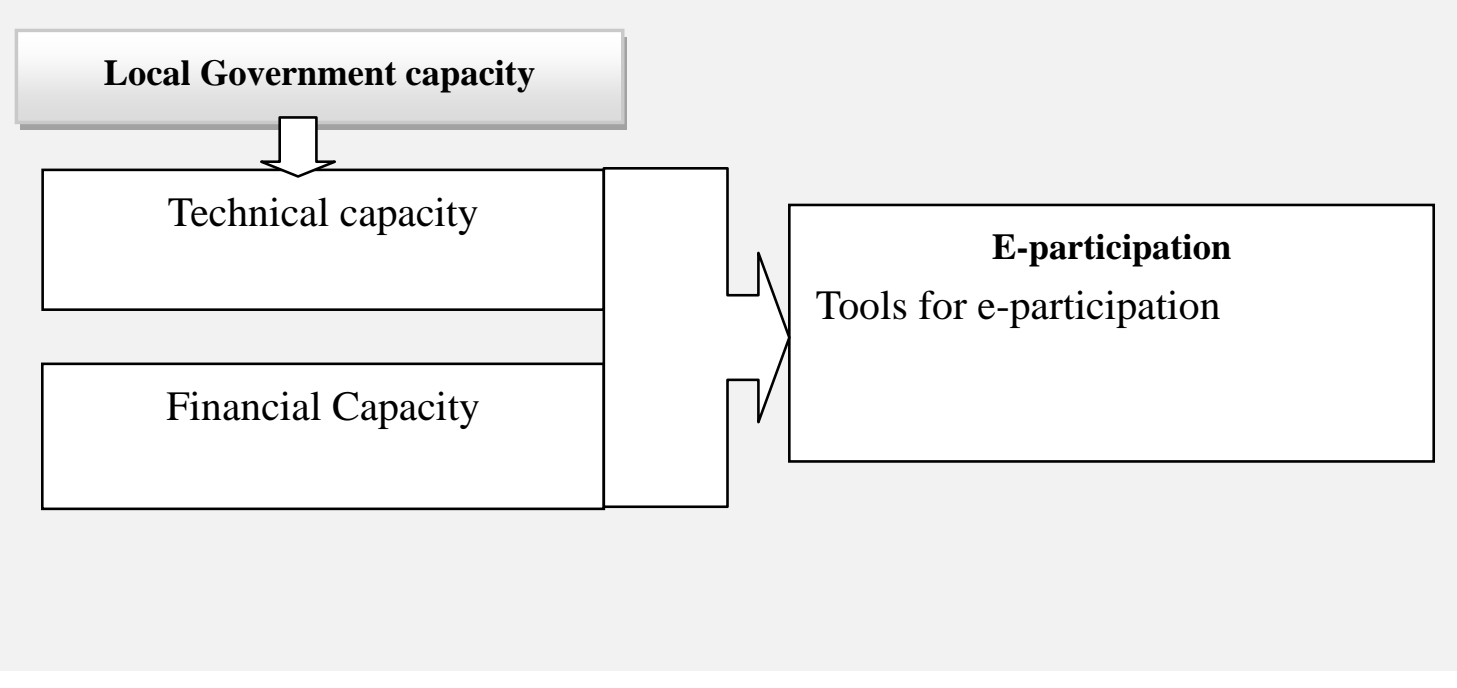

Figure 1. Conceptual framework of the study

\section{Methodology}

\subsection{Area of the Study}

This study was conducted in Kinondoni Municipal Council (KMC), which is one of the five municipalities of Dar-es-Salaam city in Tanzania. The KMC was selected purposively due to the presence of Information, Communication and Technology (ICT) in the municipality. $\mathrm{KMC}$ is one of the urban local government authorities in Tanzania. The main purpose of having local government authorities is to transfer authority to the people according to article 146 (1) of the constitution of United Republic of Tanzania. It is expected that, the use of e-participation in local government authorities will facilitate effective involvement of citizens in government affairs.

\subsection{Sample Size and Sampling Techniques}

The study population comprised 400 employees from the Kinondoni Municipality which is obligated with the responsibility of providing social services to the people. A sample size of 80 respondents was used in this study. Slovin formula developed by Robert Slovin was used to calculate the sample size of the study. Purposive sampling was used to select key informants such as one Mayor, one Municipal Director, 66 employees, four Councillors, three Heads of department, and five Heads of sections who were part of the in-depth interview. The key informants were selected because they had information on ICT and e-government. Simple random sampling was used to select employees of the municipality.

\subsection{Data Collection and Analysis}

Sixty six questionnaires were administered to the employees of the municipality and the information elicited from the questionnaire focused on the technical capacity, IT Expertise, financial capacity and availability of e-participation tools at Kinondoni municipality. 
Technical capacity was measured on the availability IT infrastructure and ability of the employees to use the IT infrastructure. Financial capacity focused on maintaining and upgrading IT infrastructures as well availability funds for recruiting and training IT staff. In-depth interview were used to extract views of Mayor, Municipal Director, and Heads of the department. The interview with key informants intended to get information on availability of IT infrastructure and human capacity on IT infrastructure on e-participation.

Descriptive approaches were used to analyse the frequency and percentage of responses on availability IT infrastructure and ability of the employees in using IT infrastructure, maintaining and upgrading IT infrastructures as well availability of funds for recruiting and training IT staff. Respondents were asked if there were e-participation tools and if citizens can access the e-services from the municipal. Likert scale measurement with a coded number such as 1 Strongly Agree, 2- Agree, 3 Neutral, 4-Disagree, 5-Strongly Disagree were used. It was assumed that e-participation development needs sufficient financial resources to invest in modern IT, training employees, IT infrastructure, and recruit technicians. Analysis of data in the study was performed by using statistical software of IBM SPSS Statistics Version 20 to give frequencies and percentages.

\section{Findings and Discussion}

\subsection{Technical Capacity}

In respect to technical capacity respondents were asked whether $\mathrm{KMC}$ had tools for e-participation. The findings indicated that out of 80 respondents, the majority $33.7 \%$ (60) mentioned Emails and 36\% (64) indicated Websites. The rest $17.4 \%$ (31) of the respondents indicated Blogs and 12.9\% (23) indicated social networks. Results suggest that Websites and Emails were the major tools of e-participation at KMC. This finding implies that e-information and e-consultation tools were not being utilized effectively by the municipality and there are no other options for informing and engaging citizens about policy plans and government decisions. While reviewing KMC website it was found that the available information was on contact of $\mathrm{KMC}$, structure, tenders, publications and tenders announcements. The website as a tool is used to inform citizens on the services provided and not for e-consultation and e- decision making. This implies that the capacity of KMC in engaging citizens in government administration is poor. Sobaci (2010) argues that ICT offers new chances and new channels for public to participate in the process of decision-making however in this municipality it seems there are no chances for public to participate in municipality decision making apart from receiving information. The results confirm that KMC has weak capacity to provide local government services through e-participation.

Furthermore, while reviewing the KMC website it was found that some of the information was outdated. A study by Zheng (2015) also indicated similar results where government at the municipal levels failed to update the information. Failing to update information indicates that the $\mathrm{KMC}$ web was not utilised by the citizens as required.

\subsection{Training on IT}

For effective e-participation, employees need to be trained on Information technology and 
how to use e-participation tools. Respondents were asked whether they received any training for effective use of e-participation tools. Findings show that $45.5 \%$ (30) of the respondents disagreed, and $13.6 \%$ (9) of the respondents strongly agreed that government employee in the municipal receives timely IT training. Moreover, 29\% (7) of the respondents strongly disagreed, $3 \%$ (2) strongly agreed while $12.1 \%$ (18) neither agreed nor disagreed. Findings show that the KMC employees do not receive IT training and this is one of the causes affecting the ICT capacity and lowers the use of e-participation tools. One of the interviewee said;

"Majority of KMC employees do not have IT knowledge and there is no fund allocated for training”

Furthermore respondents were asked whether KMC has enough staff with adequate ICT expertise. The findings indicated that out of 66 respondents, majority $(45.5 \%)$ of the respondents disagreed and $10.6 \%$ strongly disagreed that the municipality has enough staff with adequate ICT skills. Lack of staff with adequate ICT skills has relationship with lack of timely IT training which can enhance the use of e-participation tools. The shortage of staff decreases efficiency of the municipality in utilizing e-participation tools. Thus, employees in the municipal should be enhanced with training to increase the capacity of using IT facilities. These findings are supported by Talukder (2012) who concluded that the adoption of innovation is highly influenced by the amount of training provided to employees since it promotes employees awareness, attitude, skills and knowledge that improves better work performance. Talukder further clarifies that, if the intended training and awareness are provided, it will reduce some of the hindrances that slow down the adoption of technology. The results suggest that if staff in the municipal receives timely training it will increase utilisation of e-participation. The local government can only be effective in providing services through e-participation if and only training is provided to staff on IT.

\subsection{Availability of IT Facilities}

The study also intended to know whether the municipal has adequate IT facilities. Findings show that $40.9 \%$ (27) of the respondents agreed and $10.6 \%$ (7) strongly agreed. Moreover, $33.3 \%$ (22) of the respondents disagreed and $6.1 \%$ (4) of the respondents strongly disagreed while $9.1 \%$ (6) of the respondents neither agreed nor disagreed. One of the heads of section during the interview stated that;

"We lack IT skills and computer facilities hence we are suggesting IT should be given priority during budgeting"

The result of this study confirms the KMC has not invested in IT skills as well as computer facilities. The study concludes that e-participation will never be realised in a situation where computer facilities are not available.

\subsection{Financial Capacity}

The study investigated as to whether KMC had financial capacity to implement e-participation. Respondents were asked whether KMC had financial capacity to maintain 
ICT, recruit experts of IT and train their staff on the same. Findings indicated that $50 \%$ (33) of the respondents disagreed, $21.2 \%$ (14) agreed, 9.1\% (6) strongly agreed while $19.7 \%$ (13) of the respondents neither agreed nor disagreed. Findings revealed that the majority of the respondents argued that the municipality has no limited funds for maintaining and upgrading IT. These findings are in line with the $45.5 \%$ (30) of the respondents who disagreed and $6.1 \%$ (6.1) of the respondents who strongly disagreed that the municipality adequate funds for maintaining and managing the website and internet connectivity. These findings imply that without strong financial capacity it is difficult to increase technical capacity of the KMC on e-participation.

Regarding recruitment of expertise in IT, the findings indicated that $48.5 \%$ of the respondents disagreed, $7.6 \%$ strongly agreed, $22.7 \%$ agreed, 3\% (2) strongly agreed, and $18.2 \%$ (12) of the respondents neither agreed nor disagreed that the municipality has enough financial resources for recruiting IT workforce. Findings revealed that the majority of the respondents argued that the municipality has inadequate funds for recruiting IT workforces. It was found that all local authorities in Tanzania including KMC do not have autonomy to recruit IT staff and other staff of other categories as recruitment is centralized and done by the central government. This finding implies that sometimes there are external factor which decrease effectiveness of e-participation in local government especially on the aspect of recruitment of IT staff. The financial capacity is a factor that acts as important requirement that is needed to guarantee progress of e-participation in the municipality. The financial capacity serves as a foundation for another capacity mainly technical capacity. The lack of financial capacity on recruiting IT staffs results in the poor performance of e-participation in the municipality. Respondents were also asked whether KMC has financial resources for training IT staff. The findings indicated that $48.5 \%$ of the respondents disagreed and $4.5 \%$ strongly disagreed that the municipality has enough financial resources for training IT staff. The rest of the respondents $19.7 \%$ (13), 7.6\% (5), and 19.7\% (13) of the respondents agreed, strongly agreed and neither agreed nor disagreed respectively. Thus, the majority of the respondents during the study argued that the municipality has no sufficient financial resources for training IT workforce. Municipal Treasurer stated that:

Since the responsibility of the municipal is to link and receive information from several areas of our citizens, we are facing a lot of challenges including financial ability. Many of employees in the municipal have no IT knowledge since the government has no fund to train employees.

It can be concluded that the failure of the municipality to fund IT training to the employees, lowers the capacity of the employees to utilize the tools of e-participation and the capacity of e-participation in the municipality as well.

The study also intended to find out whether the municipality has adequate financial resources for collecting and managing e-participation data. Findings revealed that $40.9 \%$ of the respondents disagreed, $10 \%$ strongly disagreed while $24.2 \%$ agreed, $7.6 \%$ (5) strongly disagreed, and $16.7 \%$ (11) of the respondents neither agreed nor disagreed that the municipality has enough financial resources for collecting and managing e-participation data. 


\section{Macrothink}

Journal of Public Administration and Governance

ISSN 2161-7104

2019, Vol. 9, No. 4

Findings revealed that the majority of the respondents indicated that the municipality has no adequate financial resources for collecting and managing e-participation data. E-participation requires long-term funding for updating of software and infrastructures, as well as training municipality workers. The study by Kim and Bretschneider (2004) indicated that financial support from the government is essential for maintaining and developing adequate levels of hardware and software, and training end-users as needed. These findings support findings by Zheng (2015) where one-third of the municipalities claimed that they do not have sufficient funds for maintaining and upgrading IT infrastructure.

Zheng (2015) also came up with similar findings where almost one-half of the municipalities lack sufficient funds for recruiting IT workforces. The financial capacity serves as a foundation for another capacity mainly technical capacity. The lack of financial capacity on recruiting IT staff results to poor performance of e-participation in the municipality. Furthermore findings showed that the municipality has no financial capability to train the available IT staff. This reveals that the financial capacity is a significant factor for strengthening technical capacity in the municipality.

\section{Conclusion and Recommendations}

This study examined technical, human and financial capacity of KMC on e-participation. The findings indicated that there was no provision of e-information and e-consultation to the citizens in the municipality. The study concludes that KMC has no capacity to involve citizens in policy issues and decision-making. It is further concluded that lack of IT skills and expertise among the municipal staff are the obstacles to increasing municipal capacity on e-participation. Investment in IT is a necessary ingredient of effective citizen engagement in government policies. The study recommends that the government of Tanzania should allocate adequate budgets to the municipality to enhance the performance of e-participation by recruiting IT staff, maintaining and upgrading IT facilities as well as training IT staff. Furthermore KMC needs to provide adequate training to their employees for effective implementation of e-participation. In e-participation expertise on ICT is needed for effective citizen's participation in the processes of government policy matters.

\section{References}

Abu Shanab, E., \& Al-Dalou, R. (2012). E-participation levels and technologies. The 6th International Conference on Information Technology. (ICIT 2013), At: Amman, Jordan.

Albrecht, S., Kohlrausch, N., Kubicek, H., Lippa, B., Märker, O., Trénel, M., \& Wiedwald, C. (2008). E-participation-electronic participation of citizens and the business community in eGovernment. Study on Behalf of the Federal Ministry of the Interior (Germany), Division IT, $1(1)$.

Barney, J. (2001). Is the Resource-Based "View" a useful perspective for strategic management research? Academy of Management Review, 26(1), 41-56. https://doi.org/10.5465/amr.2001.4011938

Colbert, B. A. (2004). The complex resource-based View: Implications for theory and 
practice in strategic human resource management. Academy of Management Review, 29, 341-358. https://doi.org/10.5465/amr.2004.13670987

Donnell, O., Boyle, R., \& Timonen, V. (2003). Transformational aspects of e-Government in Ireland: issues to be addressed. Electronic Journal of E-Government, 1(1), 23-32.

Glassey, O. (2010). A survey on participation at Geneva's constituent assembly. Lecture Notes in Computer Science, 6229, 151-161. https://doi.org/10.1007/978-3-642-15158-3_13

Hart, S. L. (1995). A natural-resource-based view of the firm. Academy of Management Review, 20, 986-1014. https://doi.org/10.5465/amr.1995.9512280033

Kim, H. J., \& Bretschneider, S. (2004). Local government information technology capacity: An exploratory theory. In System Sciences, 2004. Proceedings of the 37th Annual Hawaii International Conference on (p. 10-pp). IEEE.

Krishna, S., \& Madon, S. (2003). The Digital Challenge: Information Technology in the Development Context.( $1^{\text {st }}$ edition). Ashgate Publishing Limited, Hampshire.

Kyere, F., \& Kumah Gyamea, N. Y. (2017). The imperative of e - participation in sustainable community development in Ghana. Journal of Public Administration and Governance, 7(4), 211-223. https://doi.org/10.5296/jpag.v7i4.12197

Macintosh, A. (2008). Founations of digital government and public policy. E-democracy and e-participation research in Europe. Springer, Boston, MA. (Chapter 5). https://doi.org/10.1007/978-0-387-71611-4_5

Macintosh, A., \& Whyte, A. (2008). Towards an evaluation framework for e-participation. Transforming Government: People, Process and Policy, 2(1), 16-30. https://doi.org/10.1108/17506160810862928

Okioga, C. K. (2012). Strategies which are key to the success of the corporate institution in Kenya: A case of selected corporate institutions in Kenya. European Journal of Business and Management, 4(15), 31-43.

Phang, C. W., \& Kankanhalli, A. (2008). A framework of ICT exploitation for e-participation initiatives. Communications of the ACM, 51(12), 128-132. https://doi.org/10.1145/1409360.1409385

Reddick, C., \& Norris, F. D. (2013). E-participation in local governments: An examination of political-managerial support and impacts. Transforming Government: People, Process and Policy, 7(4), 453-476. https://doi.org/10.1108/TG-02-2013-0008

Sæbø, Ø., Rose, J., \& Skiftenes Flak, L. (2008). The shape of eParticipation: Characterizing an emerging research area. Government Information Quarterly, 25(3), 400-428. https://doi.org/10.1016/j.giq.2007.04.007

Singh, H., \& Mahmood, R. (2014). Manufacturing strategy and export performance of small and medium enterprises in Malaysia: Moderating role of external environment. International Journal of Business and Commerce, 3(5), 37-52. 
Sobaci, Z. (2010). What the Turkish parliamentary web site offers to citizens in terms of e-participation: A content analysis. Information Polity. The International Journal of Government \& Democracy in the Information Age, 15(3), 227-241. https://doi.org/10.3233/IP-2010-0209

Talukder, M. (2012). Factors affecting the adoption of technological innovation by individual employees: An Australian study. Procedia-Social and Behavioral Sciences, 40, 52-57. https://doi.org/10.1016/j.sbspro.2012.03.160

White, C. S. (1997). Citizen participation and the Internet: Prospects for civic deliberation in the information age. The Social Studies, 88(1), 23-28. https://doi.org/10.1080/00377999709603741

Zheng, Y. (2015). Explaining government performance on e-participation in New Jersey: Government capacity and willingness. A Dissertation Submitted in Fulfilment of the Requirements for the Award of Degree of Doctor of Philosophy in Public Administration of Rutgers University-Graduate School-Newark.

\section{Copyright Disclaimer}

Copyright for this article is retained by the author(s), with first publication rights granted to the journal.

This is an open-access article distributed under the terms and conditions of the Creative Commons Attribution license (http://creativecommons.org/licenses/by/4.0/). 